\title{
A Linear Control System Model for Risk Reserves
}

\author{
B. Pasik-Duncan ${ }^{1}$ P. Mandl $^{2}$ T. E. Duncan ${ }^{3}$ \\ 1 Department of Mathematics \\ University of Kansas \\ Lawrence, KS 66045, USA \\ bozenna@math.ku.edu \\ 2 Department of Probability and Mathematical Statistics \\ Charles University \\ Prague, Czech Republic \\ mandl@karlin.mff.cuni.cz \\ ${ }_{3}^{3}$ Department of Mathematics \\ University of Kansas, Lawrence \\ KS 66045, USA \\ duncan@math . ku .edu
}

Keywords: Linear system, stochastic control, risk reserves

\section{Introduction}

Linear control theory was apparently initially applied to the modelling of the reserve funds for a property/casualty insurance company by MartinLöf ((4)). Even at that time an intensive development of computer simulation models of the insurance industry had been initiated. Most of the current large scale models concentrate on financial modelling and on testing deterministic scenarios. Nonetheless, as it is documented in (2) on workmen's compensation insurance, stochastic simulation models are required for the evaluation of the uncertainty in the claims' reserves. Therefore it is important to consider this facet of insurance models and to devote research to their mathematical aspects. It has been noted that the scope of the computational risk theory methods is wider than was expected when some approximations to probability distributions, that were a substantial part of risk theory until the 1980's, are employed.

\section{Main Topics}

A discrete time, linear, stochastic control system is constructed to model the risk reserves for an insurance company. The model has the autoregressive form. A control is used to regulate the risk reserve. The sequence of controls is determined by two approximations, the normal power approximation of order two and a log normal approximation. These approximations use the first three moments which incorporate the skewness of the distributions that is important for these problems. An example of automobile insurance is considered to compare the two approximations for the stationary control law. It is shown that the two approximations are given stationary controls that closely agree.

\section{REFERENCES}

[1] C. D. Daykin, T. Pentikäiaen, and M. Pesonen (1994): Practical risk theory for actuaries, vol. 53 of Monographs on Statistics and applied Probability, Chapman and Hall Ltd., London. (1808): Faust. Weimar, ABC Verlag.

[2] D. M. Hodes, S. Feldblum, and G. Blumsohn (1996): Workers compensation reserve uncertainty. In CAS forum, pp 61 - 150.

[3] P. Mandl, V. Sroller, and Vsetulova (1996): On the transition form the ex-lege MTPL Insurance to the compulsory contractual form, Pojistne Rozpravy, XII 19 - 27, in Czech.

[4] Anders Martin-Löf (1983): Premium control in an insurance system, an approach using linear control theory, Scand. Actuar. (1) 1 - 27. 